\title{
Delirium in Patients with Substance Abuse: A Case-Series
}

\author{
Carla Gramaglia, Sabrina Gili, Alessandro Feggi, Eleonora Gattoni, Patrizia Zeppegno* \\ Institute of Psychiatry, Dipartimento di Medicina Traslazionale, Università del Piemonte Orientale "Amedeo \\ Avogadro", Novara, Italy \\ Email: ${ }^{*}$ patrizia.zeppegno@med.unipmn.it
}

Received 1 April 2014; revised 1 May 2014; accepted 30 May 2014

Copyright @ 2014 by authors and Scientific Research Publishing Inc.

This work is licensed under the Creative Commons Attribution International License (CC BY).

http://creativecommons.org/licenses/by/4.0/

(c) (i) Open Access

\begin{abstract}
Severe agitation in patients with delirium may be difficult for clinicians' management because of problems of differential diagnosis and treatment. Regrettably, theory and guidelines concerning this issue may fail to cover the incredible complexity of clinical practice. Our aim is to describe three cases of delirium from our real-life clinical experience, with a specific focus on their complexity as far as differential diagnosis and psychopharmacological treatment are concerned. In clinical practice, as shown by the three cases we describe, the etiology of delirium is various and mixed, lab analysis are not specific and it is not possible to exactly assess which kind of substances were used by patients. New drugs and smart drugs are not yet detectable by our urine analysis, and their effects, interaction with prescription drugs and pharmacokinetics are not well known. With the aim to obtain a successful sedation and to calm the patient, in our cases, we needed to use a pharmacological combined approach (benzodiazepines, first and second generation antipsychotics) with different routes of administration and, when inevitable, physical restraint.
\end{abstract}

\section{Keywords}

Delirium, Agitation, Psychosis, Substance Abuse

\section{Introduction}

Delirium is a disturbance of consciousness, attention, cognition, and perception but can also affect sleep, psychomotor activity, and emotions. It is a common psychiatric disorder among medically compromised patients and it should be considered a sentinel of significant morbidity and mortality. The main causes of delirium may be: central nervous system, metabolic, and cardiopulmonary disorders, and systemic illness. Several substances

${ }^{*}$ Corresponding author.

How to cite this paper: Gramaglia, C., Gili, S., Feggi, A., Gattoni, E. and Zeppegno, P. (2014) Delirium in Patients with Substance Abuse: A Case-Series. Open Journal of Psychiatry, 4, 163-167.

http://dx.doi.org/10.4236/ojpsych.2014.43021 
can cause delirium through intoxication or withdrawal, including drugs of abuse, medications anesthetics and toxins [1].

Agitation is one of the symptoms of delirium and is defined as "a request to which an answer cannot be deferred” [2]. It can be described as excessive motor or verbal activity, which can present as assault, verbal abuse, threatening gestures and language, and physical destructiveness [3]. Agitation may be due to a medical condition or be a manifestation of a mental illness. With more detail, a common accompanying factor that complicates psychotic agitation is concomitant abuse of alcohol and illicit drugs, which increases the risk of aggression [4]. Substances with psychotomimetic properties such as cocaine, amphetamines, hallucinogens and cannabis are widespread, and their use or abuse can provoke psychotic reactions resembling a primary psychotic disease. Concomitant substance use by subjects with a psychotic illness, especially in young users with an early-phase psychotic disorder, can make diagnosis difficult [5]. Furthermore, thorough laboratory analysis only a few substances can be detectable, while new substances of abuse are not yet identifiable.

It should be noted that differential diagnosis is crucial to focus the therapeutic approach, and should be performed on the basis of symptomatology (level of consciousness, language,...) as well as on information provided by family members, friends or witnesses (psychiatric or medical history of organic disease, precipitating factors, drug use or withdrawal, type of onset, previous episodes and duration,...) [6].

Regrettably, theory and guidelines concerning this issue may fail to include the incredible complexity of clinical practice. Therefore, our aim with this article is to describe three cases of delirium with severe agitation from our real-life clinical experience, since we believe that sharing experiences from everyday practice may be particularly useful in a field where guidelines may be difficult to apply.

(Please note that in the following cases, when we mention intravenous administration, we make reference to prescription drugs dilute in physiological saline solution with different concentration.)

\section{Case 1}

Male, 26 years old. Caucasian ethnicity. Unemployed. History of seizures and drug abuse (cannabis and cocaine, daily) since young age, but no previous contact with psychiatric services. Familiar medical history silent for psychiatric or neurological diseases.

Admitted to Emergency Room (ER) after shooting himself in right orbital bone while intoxicated. Urine lab analysis positive for cocaine and cannabinoids. The next day, after the bullet surgical removal, the patient was mechanically ventilated and sedated with Propofol intra-venous (IV) $(15 \mathrm{ml} / \mathrm{h} ; 360 \mathrm{ml} /$ day) and Remifentanil IV ( $8.0 \mathrm{ml} / \mathrm{h} ; 192 \mathrm{ml} /$ day). Other medications were: Omeprazole IV $40 \mathrm{mg} /$ day; Ampicillin/Sulbactam IV 9 gr/day; Levetiracetam IV 1000 mg/day; Betamethasone Oral Route (PO) 16 mg/day; Enoxaparine Subcutaneous 4000 UI; Clonidine IV (13 ml/h; $312 \mathrm{ml} /$ day).

Any attempt of extubation and reduction of therapy exacerbated an acute agitation with confusion and psychomotor restlessness. For this reason, a Psychiatric consultation was required and treatment was prescribed with introduction of Delorazepam IV 15 mg/day, Promazine 75 intra-muscular (IM) mg/day. After four days, the patient was still agitate, needing a physical restraint and additional therapy: Clonidine IV $(13 \mathrm{ml} / \mathrm{h} ; 312$ ml/day); Midazolam IV (4 ml/h; 96 ml/day); Haloperidol IM (6 mg/day); Clotiapine PO (120 mg/day). Agitation persisted but was less marked: the patient began to ask to see his mother or to go home.

The patient was eventually admitted to the Psychiatric Ward with a diagnosis of mixed causes delirium (cocaine and cannabis intoxication, history of seizures, head and facial trauma with consequent surgical intervention) and started medication with Sodium Valproate PO $1000 \mathrm{mg} /$ day in addition of previous treatment. After three days of treatment symptoms gradually decreased and the patient calmed down.

\section{Case 2}

Man, 33 years old, Caucasian, single, only child, parents living, working as hydraulic. No history of previous psychiatric disorders; maternal grandmother with Alzheimer. He had an inguinal hernia surgery; Hepatitis C positive; irregular sleep-wake rhythm. He smokes about ten cigarettes/day since the age of 15 years old. He has a history of alcohol and substance abuse: cannabis, heroin, cocaine, hallucinogens. Since 2010 the patient is treated by the drug addiction Services and is currently taking Methadone.

The patient presented acute agitation with confusion, psychomotor restlessness, bizarre behavior and aggressiveness, persecutory and megalomaniac delusion and ideas of reference. Urine analysis were positive for can- 
nabis (107 ng/mL); negative for amphetamines, heroin, cocaine and benzodiazepines. The diagnosis at intake in the Psychiatric Ward was delirium caused by substance intoxication. During the hospitalization he was treated with Aripiprazole IM 22.5 mg/day then replaced with Haloperidol IM 6 mg/day, Clotiapine PO 100 mg/day, Delorazepam IV $2 \mathrm{mg} / \mathrm{day}$. After 8 days of treatment we observed a gradual decrease of symptoms and the patient calmed down.

After 9 hours since discharge from the hospital he returned in ER presenting again confusion, psychomotor restlessness, bizarre behavior, aggressiveness and delusions. Urine analysis were positive for cannabis ( $>135$ $\mathrm{ng} / \mathrm{mL}$ ). The patient was treated with Delorazepam IV $20 \mathrm{mg} /$ day, Clotiapine IM $2 \mathrm{mg} /$ day, Promazine IV 50 $\mathrm{mg} /$ day and physically restrained; nonetheless, he was still severely agitated. For this reason he was moved to ER with the aim of obtaining a deeper level of sedation: he was treated with Propofol IV $1.2 \mathrm{mg} / \mathrm{kg} / \mathrm{h}$ (the maximum dosage), Haloperidol IM 8 mg/day and Clotiapine IM 120 mg/day. Propofol was decreased and then suspended within 2 days: the patient was only partially calm, still confused and disoriented; he was moved again to the Psychiatric Ward.

\section{Case 3}

31-year-old man, Caucasian. Family history: father affected by Bipolar Disorder. He has a history of substance abuse: daily consume of heroin and crack cocaine in the last 12 years. Since 2002 the patient is treated by the drug addiction Services and is taking Methadone. 3 months before the admission in our hospital, he has started showing psychotic symptoms including persecutory delusions and ideas of reference concerning his partner and law enforcement.

He is admitted to Hospital after attempting suicide with a firearm, shooting himself in oral cavity. After the removal of the bullet, he was moved to our Psychiatric Ward. Urine analysis were positive for heroin $(>1000$ $\mathrm{ng} / \mathrm{mL}$ ), cocaine (>5000 $\mathrm{ng} / \mathrm{mL})$, cannabis $(57 \mathrm{ng} / \mathrm{mL})$, methadone $(3543 \mathrm{ng} / \mathrm{mL})$; negative for amphetamines and benzodiazepines. The diagnosis at intake was mixed causes delirium (heroin, cocaine and cannabis intoxication, facial trauma with removal of the bullet). Maximum dosage of therapeutic drugs used: Haloperidol PO 5 mg/day, Delorazepam IV 10 mg/day, Promazine IV 100 mg/day, Methadone PO 60 mg/day.

During the first days of hospitalization the patient was agitated, anguished, intolerant and uncritical toward the illness. 9 days after the failed attempted suicide the patient was moved to another hospital for lower intensity care to continue the therapeutic project. We observed a reduction of symptoms, but the patient was still totally uncritical toward the delusions and the suicide attempt.

\section{Discussion}

The three cases described make it easy to understand how complex may be to deal with severely agitated patients with delirium caused by multiple etiological factors. In these patients we observed a state of agitation, psychomotor restlessness, confusion and psychotic symptoms. Our case series presented young (Case 1-26 years old, Case 2-33 years old, Case 3-31 years old) patients without cardiac, hepatic or renal failure; Case 1 suffered from epilepsy, Case 2 was positive for Hepatitis C virus with no clinical and lab sign of hepatic damage. All the patients had a history of previous substance abuse, two of them were treated by drug addiction Services with supportive psychotherapy and Methadone, but none of them had previously required hospitalization in a Psychiatric Ward.

These 3 patients had a delirium caused by various and concurrent etiologies: substance intoxication or withdrawal (amphetamines, cannabis, cocaine, hallucinogens, opioids); head/severe trauma; sensory deprivation; postoperative state; seizures.

As suggested by the American Psychiatric Guidelines an essential principle in the psychiatric management of delirium is the identification and correction of the etiologic factors [1]. Anyway, as described in our case series, and as frequently happens in clinical practice, it is not so simple to apply this advice: as shown before the etiology is various and mixed, lab analysis are not specific and it is not possible to exactly assess which kind of substances were used by patients. New drugs and smart drugs are not yet detectable by urine analysis, and their effects, their interaction with prescription drugs and pharmacokinetics are not well known. Therefore the observed profile of sedation was significantly lower than expected considering drug and dose used, probably depending on the substances abuse/withdrawal. Moreover, in our case series agitation and other symptoms lasted more than could be expected for a delirium due to a single cause and we noticed a later onset of recovery. 
Considering all these issues we decided to treat our patients with a relatively safe, handy and cliniciansfriendly medication approach as mentioned by Allen 2005: when no patient data are available, or the diagnosis includes medical comorbidity or state of intoxication, none of the new Second Generation Antipsychotic (SGA) parenteral formulations received as much support as traditional agents (Benzodiazepines IM, Haloperidol IM) [7]. When these patients were treated, IV and IM Lorazepam formulation was not available in our hospital, so we used Delorazepam. When antipsychotic monotherapy plus benzodiazepines was not efficient [Delorazepam (Case 1: 15 mg IV; Case 2: 20 mg IV; Case 3: 10 mg IV), Haloperidol (Case 1: 6 mg IM; Case 2: 8 mg IM; Case 3: $5 \mathrm{mg}$ PO)], we implemented therapy with other First Generation Antipsychotic (FGA) like Promazine (case 1: 75 mg IM; Case 2: 50 mg IV; Case 3: 100 mg IV) and Clotiapine (Case 1 and 2: 120 mg PO) [Table 1].

FGA are often related to Extrapyramidal Symptoms (EPS), that in our case series did not occur. Benzodiazepines were also used for their well-known sedative properties. Considering that Benzodiazepines could impair respiratory function, especially in a patient which had used opioid drugs, these were used as a second line treatment. Antidote treatment with Flumazenil was not necessary in our case series.

When pharmacological approach alone was not effective, physical restraint was performed (Case 1 and Case 2) for the shortest time possible, and vital parameters (blood pressure, heart rate, O2 saturation and temperature) were monitored every 2 hours.

\section{Conclusions}

According to guidelines the primary goal of interventions in cases as the ones described is to secure the safety of the patient, staff, and other patients. The first step in the management of the agitated and aggressive patient should be talking to him/her and offering help if needed. The next step is a decision to initiate oral drug treatment. If necessary, time-limited restraints or placement into seclusion may be used. Restraints should be used only when the patient poses an imminent danger to himself or others and when other less restrictive means failed [8]. Their use is temporary ( 2 - 4 hours); their application should be used to initiate treatment and to provide basic physical, instrumental and laboratory assessments. Patients in restraints usually calm down after a while [9]. Although oral treatment is preferred, options in the pharmacotherapy of acute agitation include the parenteral (IM and/or IV) administration of the psychotropic drugs in order to facilitate onset of drug action and quickly alleviate symptoms. So-called rapid tranquilization is the repeated administration of medication over brief time intervals, usually within an hour or half-hour period [10]. The goals of pharmacologic therapy for agitation include: 1) calming the patient without oversedation, 2) decreasing dangerous and aggressive behaviors, and 3) allowing treatment of the patient's underlying disease by the health care team [11].

In order to treat delirium we have to consider that in clinical practice causes of delirium are often more than one. With the aim to obtain a successful sedation and to calm the patient, in our cases, we needed to use a pharmacological combined approach (benzodiazepines, FGA and SGA) with different routes of administration and, when inevitable, physical restraint.

\section{Funding}

This research received no specific grant from any funding agency in the public, commercial, or not-for-profit sectors.

Table 1. Pharmacological treatments used in the three cases.

\begin{tabular}{|c|c|c|c|c|}
\hline \multirow{9}{*}{$\begin{array}{l}\text { Treatment } \\
\text { (Max } \\
\text { Dosage) }\end{array}$} & & $\begin{array}{c}\text { CASE } 1 \\
\text { (cocaine and cannabis) }\end{array}$ & $\begin{array}{c}\text { CASE } 2 \\
\text { (cannabis) }\end{array}$ & $\begin{array}{c}\text { CASE } 3 \\
\text { (heroin, cocaine, cannabis) }\end{array}$ \\
\hline & Haloperidol & $6 \mathrm{mg}$ IM & $8 \mathrm{mg}$ IM & $5 \mathrm{mg} P O$ \\
\hline & Clotiapine & 120 mg PO & 120 mg PO & \\
\hline & Promazine & 75 mg IM & $50 \mathrm{mg}$ IV & $100 \mathrm{mg}$ IV \\
\hline & Delorazepam & $15 \mathrm{mg}$ IV & $20 \mathrm{mg}$ IV & $10 \mathrm{mg} I V$ \\
\hline & Aripiprazole & & $22.5 \mathrm{mg}$ IM & \\
\hline & Midazolam & $96 \mathrm{ml} \mathrm{IV}$ & & \\
\hline & Propofol & $360 \mathrm{ml} \mathrm{IV}$ & $360 \mathrm{ml} \mathrm{IV}$ & \\
\hline & Remifentanil & $192 \mathrm{ml} \mathrm{IV}$ & & \\
\hline
\end{tabular}




\section{Conflict of Interest}

None declared.

\section{References}

[1] American Psychiatric Association Steering Committee on Practice Guidelines, Practice Guideline for the Treatment of Patients with Delirium, 1999.

[2] Bakay, S., Iweins, A., Scantamburlo, G., Ansseau, M. and Pitchot, W. (2013) The Acute Management of Agitation. Revue Médicale de Liège, 68, 553-556.

[3] Allen, M.H., Currier, G.W., Hughes, D.H., Reyes-Harde, M. and Docherty, J.P. (2001) The Expert Consensus Guideline Series. Treatment of Behavioral Emergencies. Postgraduate Medicine (Spec No), 1-88; quiz 89-90.

[4] Volavka, J. (2002) Neurobiology of Violence. 2nd Edition, American Psychiatric Publishing, Inc., Washington DC.

[5] Fiorentini, A., Volonteri, L.S., Dragogna, F., Rovera, C., Maffini, M., Mauri, M.C. and Altamura, C.A. (2011) Substance-Induced Psychoses: A Critical Review of the Literature. Current Drug Abuse Reviews, 4, 228-240. http://dx.doi.org/10.2174/1874473711104040228

[6] Gallego, V.F., Murcia Pérez, E., Sinisterra Aquilino, J., Casal Angulo, C. and Gómez Estarlich, M.C. (2009) Management of the Agitated Patient in the Emergency Department. Emergencias, 21, 121-132.

[7] Allen, M.H., Currier, G.W., Carpenter, D., Ross, R.W. and Docherty, J.P. Expert Consensus Panel for Behavioral Emergencies 2005 (2005) The Expert Consensus Guideline Series. Treatment of Behavioral Emergencies. Journal of Psychiatric Practice, 11 (Suppl.1), 5-108.

[8] Allen, M.H., Currier, G.W., Hughes, D.H., Reyes-Harde, M. and Docherty, J.P. (2001) The Expert Consensus Guideline Series. Treatment of Behavioral Emergencies. Postgraduate Medicine (Special number), 1-88.

[9] Tardiff, K. (1996) Assessment and Management of Violent Patients. 2nd Edition, American Psychiatric Publishing, Inc., Washington DC, 166.

[10] Mohr, P., Pečeňak, J., Švestka, J., Swingler, D. and Treuer, T. (2005) Treatment of Acute Agitation in Psychotic Disorders. Neuroendocrinology Letters, 26, 327-335.

[11] Baker, S.N. (2012) Management of Acute Agitation in the Emergency Department. Advanced Emergency Nursing Journal, 34, 306-318. http://dx.doi.org/10.1097/TME.0b013e31826f12d6 
Scientific Research Publishing (SCIRP) is one of the largest Open Access journal publishers. It is currently publishing more than 200 open access, online, peer-reviewed journals covering a wide range of academic disciplines. SCIRP serves the worldwide academic communities and contributes to the progress and application of science with its publication.

Other selected journals from SCIRP are listed as below. Submit your manuscript to us via either submit@scirp.org or Online Submission Portal.
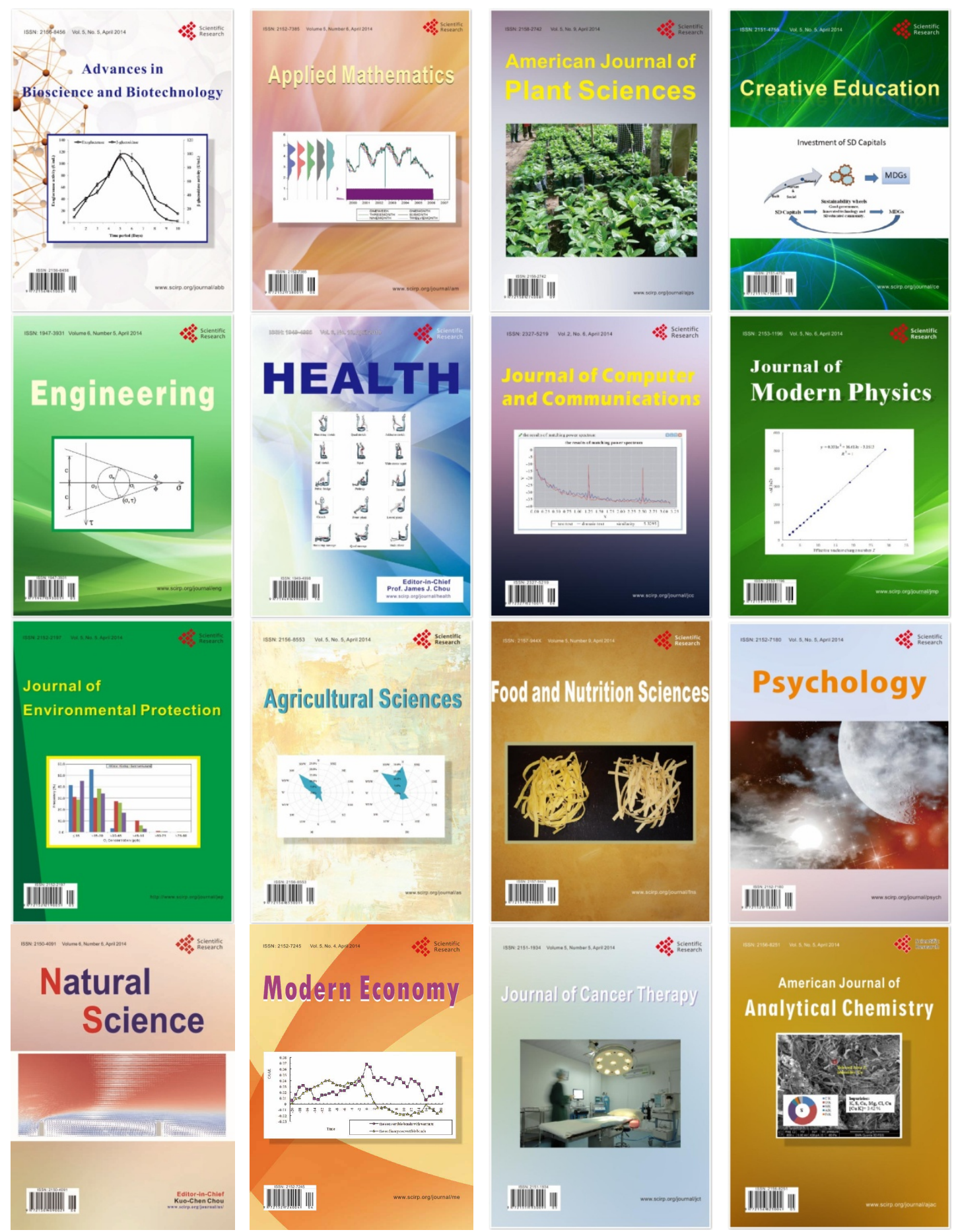